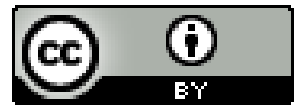

\title{
RELAÇÕES RACIAIS, UMA QUESTÃO ANTIMANICOMIAL
}

\author{
Emiliano de Camargo David ${ }^{1}$ \\ Maria Cristina Gonçalves Vicentin ${ }^{2}$
}

Resumo: Partindo do diagnóstico do racismo estrutural no país e da necessidade de assegurar equidade racial na gestão e na atenção em saúde, realizamos uma pesquisa qualitativa, na perspectiva da análise institucional, num Centro de Atenção Psicossocial Infantojuvenil (CAPSij), visando discutir saúde mental e relações raciais. Para tanto, entrevistamos profissionais desse serviço, abordando tais relações em duas dimensões: cuidado em saúde e gestão do serviço, numa discussão à luz da literatura sobre psicologia e relações raciais. O presente artigo apresenta parte dos resultados da pesquisa: inicialmente, discutimos a Política Nacional de Saúde Integral da População Negra (PNSIPN) e o Quesito Raça/Cor como importantes ferramentas de reconhecimento e intervenção em relação às iniquidades raciais em saúde/saúde mental; em seguida, apresentamos e discorremos sobre as entrevistas com o gestor e o agente administrativo do equipamento público analisado, as quais focalizaram, respectivamente, os modos como o CAPSij em questão inclui as relações raciais no seu projeto de trabalho e como aborda a coleta do quesito raça/cor. Concluímos destacando a necessária consideração das relações raciais - que chamamos de aquilombamento dos serviços de saúde - como uma questão antimanicomial. Assim, consideramos que a descolonização das práticas de cuidado e a inclusão das teorias e dos saberes afrodiaspóricos podem ampliar a potência de um agir em saúde que contribua para a promoção da equidade racial e para a desinstitucionalização do racismo.

\footnotetext{
${ }^{1}$ Psicólogo, doutorando e mestre em Psicologia Social pela Pontifícia Universidade Católica de São Paulo. Bolsista CNPQ. Integrante do Núcleo de Pesquisa em Lógicas Institucionais e Coletivas (NUPLIC - PUC/SP), integrante do Instituto AMMA Psique e Negritude e integrante do GT Racismo e Saúde da ABRASCO. É psicólogo clínico, acompanhante terapêutico e tem experiência em Psicologia Social. Atua principalmente em saúde mental e saúde da população negra, na esfera pública e privada. ORCID: https://orcid.org/0000-0002-2571-3133 E-mail: emilianocamargodavid@ yahoo.com.br

${ }^{2}$ Profa. Dra da Faculdade de Ciências Humanas e da Saúde da PUC-SP, onde coordena o Núcleo de Estudos e pesquisas Lógicas Institucionais e Coletivas do Programa de Estudos Pós-graduados em Psicologia Social. Membro do grupo de pesquisa em Direitos Humanos, Democracia, Política e Memória do Instituto de Estudos Avançados (IEA-USP) e da Rede Internacional Coletivo Amarrações (em defesa da vida dos jovens). ORCID: http://orcid.org/0000-0003-0597-9994 E-mail: cristinavicentin@ gmail.com
}

Financiamento de Pesquisa: Conselho Nacional de Desenvolvimento Científico e Tecnológico - CNPq 
Palavras-chave: Racismo; Saúde mental; Psicologia; Saúde da população negra; Reforma psiquiátrica.

\section{RELACIONES RACIALES, UNA CUESTIÓN ANTIMANICOMIAL}

Abstract: Starting from the diagnosis of structural racism in the country and the need to ensure racial equity in health management and care, we conducted a qualitative research, from the perspective of institutional analysis, in a Child Psychosocial Care Center (CAPSij) to discuss mental health and racial relations. Therefore, we interviewed professionals of this service focusing on such relationships in two dimensions: health care and service management, which were discussed in the light of the literature on psychology and race relations. This paper presents part of the research results organized as follows: we initially discussed the National Policy for Integral Health of the Black Population (PNSIPN) and the Race / Color Question as important tools of recognition and intervention in relation to racial inequalities in health / mental health. Then we present and discuss the interviews with the manager and administrative agent of the analyzed service, which focused, respectively, on how the service includes racial relations in its work project and how it experiences the collection of race / color. We conclude by highlighting the necessary consideration of racial relations as an antiasylum issue, which we call the health services aquilombamento (reunion). The decolonization of care practices and the inclusion of Afro-diasporic theories and knowledge can increase the power of health action that contributes to the promotion of racial equity and the deinstitutionalization of racism.

Keywords: racism, mental health, psychology, black population health, psychiatric reform.

\section{RELACIONES RACIALES, UNA CUESTIÓN ANTIMANICOMIAL}

Resumen: Desde el diagnóstico del racismo estructural en el país y de la necesidad de garantizar equidad racial en la gestión y en la atención en salud, realizamos una pesquisa cualitativa, por la perspectiva del análisis institucional, en un Centro de Atención Psicosocial Infantojuvenil (CAPSij), con la intención de discutir salud mental y relaciones raciales. Para tanto, entrevistamos a los profesionales de este servicio tratando de tales relaciones en dos dimensiones: el cuidado en la salud y en la gestión del servicio, en una discusión a la luz de la literatura sobre psicologia y relaciones raciales. El presente artículo presenta parte de los resultados de la pesquisa: inicialmente, discutimos la Política Nacional de Salud Integral de la Población Negra (PNSIPN) y el tópico Raza/Color como importantes herramientas de reconocimiento e intervención con relación a las inequidades raciales en salud/salud mental; a continuación, presentamos y discutimos las entrevistas con el gestor y agente administrativo del servicio analizado, que focalizaron, respectivamente, los modos cómo el servicio incluye las relaciones raciales en su proyecto de trabajo y cómo trata la recolecta del tópico raza/color. Concluimos enfatizando la necesaria consideración de las relaciones raciales - a la que llamamos aquilombamento de los servicios de salud como una cuestión antimanicomial. La descolonización de las prácticas de cuidado y la inclusión de las teorías y de los saberes afrodiaspóricos pueden ampliar la potencia del

Revista da ABPN • v. 12, n. Ed. Especial - Caderno Temático: "III ANPSINEP Articulação Nacional de Psicólogas/os Negras/os e Pesquisadoras/es” • outubro de 2020, p. 108-137 
modo de actuar en salud y contribuir para la promoción de la equidad racial y para la desinstitucionalización del racismo.

Palabras clave: racismo, salud mental, Psicología, salud de la población negra, reforma psiquiátrica.

\section{RELATIONS RACIALES, UNE QUESTION ANTI-ASILE}

Résumé: C'est à partir d'un diagnostic de racisme structural dans le pays, ainsi que le besoin d'assurer l'équité raciale dans la gestion et les soins en santé que nous avons réalisé cette recherche qualitative. Elle s'insère dans la perspective d'une analyse institutionnelle dans un Centre d'Attention Psychosocial pour des Enfants et Adolescents - CAPSii dans le but de discuter la santé mentale et les relations raciales. Pour ce faire, nous avons fait des entretiens avec le personnel à ce service en approchant telles relations par deux biais : les soins en santé et la gestion du service, en ayant le sujet illuminé par la littérature de la psychologie et relations raciales. Cet article présente une partie des résultats de la recherche. Tout d'abord nous avons discuté de la Politique Nationale en Santé Intégrale de la Population Noire (PNSIPN) et le volet d'option Race/Couleur de peau comme étant des outils importants pour la reconnaissance et aussi l'intervention par rapport aux injustices raciales en santé/santé mentale. Ensuite, nous avons présenté en forme de récit les entretiens faits avec le responsable et l'agent administratif de l'endroit publique analysé, dans lesquels ce sont mis en évidence, respectivement, les façons dont le CAPSii relève les relations raciales dans son projet de travail et comment il touche le registre de l'option Race/couleur de peau dans ses fiches. La conclusion s'est donnée par l'indispensable prise en compte des relations raciales - celles que nous appelons de 'aquilombamento' des services en santé - comme une question anti-asile. Ainsi, nous estimons que la décolonisation de pratiques de soin dans ce contexte tout comme l'inclusion de théories et savoirs afrodiasporiques peuvent élargir la potentialisation de l'action en santé afin de contribuer à l'équité raciale ainsi qu'à la désinstitutionalisation du racisme.

Mots-clés: Racisme; Santé mentale; Psychologie; Santé de la population noire; Reforme psychiatrique.

\section{INTRODUÇÃO}

Este artigo baseia-se em dissertação de mestrado em Psicologia Social ${ }^{3}$ que buscou discutir, a partir da perspectiva dos trabalhadores de um Centro de Atenção Psicossocial II Infantojuvenil (CAPSij), as relações entre atenção psicossocial e racismo, tendo como referência a literatura sobre psicologia e relações raciais (BENTO, 2002; COSTA, 2018; DAVID \& SILVA, 2018; NOGUEIRA, 1998; PIZA \&

\footnotetext{
${ }^{3}$ Sendo o primeiro autor do artigo, o autor da pesquisa e a segunda, a orientadora.
} 
ROSEMBERG, 2002; SANTOS, 2018; SCHUCMAN, 2014; SILVA, 2004) e os aportes de Achille Mbembe.

Pode-se afirmar que nos equipamentos de saúde mental em nosso país não é costumeira a discussão da temática étnico-racial, embora um número significativo de estudos (BARROS et al., 2014; HART, 2014; SCHWARCZ, 1993; SERRA \& SCARCELLI, 2014) evidenciem o preconceituoso vínculo entre loucura e população negra ao longo da história, em distintos contextos políticos.

Via de regra, a dimensão racial configura-se como uma variável sombra, na acepção que lhe dá Saraceno (1994, p. 22), isto é, aquela que é "considerada 'irrelevante' no que diz respeito à evolução da enfermidade e à estratégia de intervenção"; assim, a discussão sobre saúde mental da população negra tem ficado invisibilizada ou em segundo plano (Rosa \& Campos, 2012). Partimos do pressuposto de que o racismo é estrutural, isto é, "compõe o modo pelo qual "se constituem as relações políticas, econômicas, jurídicas e até familiares” (ALMEIDA, 2018, p. 38), operando enquanto relação de poder, sustentando privilégios, produzindo subjetividades e podendo gerar sofrimento psíquico.

Consideramos ainda que a saúde da população negra tem relação com o modo como os negros têm sido inseridos na sociedade, de forma distinta das demais raças, sendo fundamental a consideração desta dimensão nos modos de propor a gestão e atenção em saúde/saúde mental no Sistema Único de Saúde (SUS) para assegurar equidade racial.

Nessa direção, Santos (2018) afirma que o Estado não determina apenas quem deve morrer e quem deve viver, mas também "os que devem ter saúde mental, e os que podem viver atormentados em seu sofrimento produzido pelas condições sociais" (SANTOS, 2018, p. 247) além de decidir quais psicologias e quais abordagens utilizar nos cuidados em saúde.

Se a racialização pretende demarcar não apenas a existência da raça como constructo social, mas o desvelamento de uma 'ordem racial' assimétrica (MAIO \& MONTEIRO, 2005). Compreendemos que todos os humanos na modernidade são racializados (negros, brancos, indígenas, asiáticos) porém, as condições materiais e simbólicas desse processo foram/são distintas para cada grupo étnico-racial, ofertando diferentes modos de compreensão de si e dos grupos raciais existentes (David \& Silva,

Revista da ABPN • v. 12, n. Ed. Especial - Caderno Temático: "III ANPSINEP Articulação Nacional de Psicólogas/os Negras/os e Pesquisadoras/es” • outubro de 2020, p. 108-137 
2018). Essa diferenciação se revela nos coletivos atendidos nos equipamentos de saúde pública e privados de saúde mental do Brasil, pois os efeitos subjetivos desses processos também são distintos, para cada grupo racial (DAVID \& SILVA, 2018).

Considerando a importância de estudos que abordem o preconceito racial e seu impacto na saúde mental da população brasileira (SCHOLZ et al, 2014), buscamos analisar como um CAPSij realiza o cuidado dos possíveis sofrimentos psíquicos produzidos pelo racismo e como aborda a temática étnico-racial como parte da organização do serviço. Os CAPSij são serviços que assumem o protagonismo quando se trata do cuidado em saúde mental infantojuvenil, com foco no território, na intersetorialidade, na inclusão social e na garantia de direitos da infância e adolescência (BRASIL, 2015). Deste modo, encontram-se em condições estratégicas na luta antirracista na esfera do cuidado em saúde mental.

A pesquisa foi orientada por uma abordagem qualitativa e participativa, privilegiando a análise coletiva de um problema, um fazer "com", na forma de um "pesquisador coletivo" (LOURAU, 1993). Os procedimentos utilizados foram: 1) observação participante no cotidiano e participação em reuniões de equipe; 2) leitura de prontuários, (caracterização sociodemográfica dos usuários); 3) entrevistas áudiogravadas com quinze profissionais da equipe. Realizada no período de um ano, em 2017, a pesquisa foi aprovada pelos Comitês de Ética da PUC-SP e da Secretaria Municipal de Saúde e aprovado sob o número do CAEE 61689416.9.0000.5482 e número do parecer 1.854.944

Neste artigo, discutimos a Política Nacional de Saúde Integral da População Negra (PNSIPN) e o Quesito Raça/Cor como importantes ferramentas de reconhecimento e intervenção em relação às iniquidades raciais em saúde/saúde mental e apresentamos especificamente as entrevistas com gestor e agente administrativo do CAPSij que focalizaram, respectivamente, os modos como o serviço inclui as relações raciais no seu projeto de trabalho, inclusive na formulação do Projeto Terapêutico Singular do usuário, e como realiza a arguição do quesito raça-cor quando do acolhimento.

No percurso da pesquisa, foi possível evidenciar que as intervenções e os projetos terapêuticos em andamento no CAPSij em tela já trabalham com os efeitos do racismo, na medida em que seus compromissos com as práticas de liberdade e recusa 
dos processos de exclusão e violência correspondem aos pressupostos ético-políticos da luta antimanicomial. Contudo, sugere-se que a consideração dos efeitos do racismo como uma questão antimanicomial, o que chamamos de aquilombamento dos CAPS, pode ampliar a potência de um agir em saúde que contribua para a promoção da equidade racial e para a desinstitucionalização do racismo. Como já sugeria Nascimento ([1980] 2019, p. 282), o modelo quilombista vem atuando como ideia-força e energia inspiradora da organização da população negra desde o século XV em fina relação com as exigências do tempo histórico e do meio geográfico. Para esse aquilombamento, não basta dar "visibilidade" à raça como variável "sombra", até porque raça/cor foram tomadas como objeto central das propostas eugenistas e manicomiais. É necessário construir ferramentas teóricas e de cuidado em saúde para a população negra, em uma posição ético-política antirracista.

No Estatuto da Igualdade Racial (BRASIL, 2010a), o direito à saúde tem o status de capítulo primeiro. Essa posição não é uma mera coincidência, afinal, segundo dados do Portal da Saúde do SUS, em 2016, 74\% dos indivíduos que utilizaram o SUS se declararam pretos ou pardos. ${ }^{4}$

O Estatuto postula como um dos seus objetivos "a promoção da saúde integral da população negra, priorizando a redução das desigualdades étnicas e o combate à discriminação nas instituições e serviços do SUS" assim como "a melhoria da qualidade dos sistemas de informação do SUS no que tange à coleta, ao processamento e à análise dos dados desagregados por cor, etnia e gênero" (BRASIL, 2010b, p. 16).

A Política Nacional de Saúde Integral da População Negra (PNSIPN), instituída em 2010, segue a mesma linha propositiva, reconhecendo "o racismo, as desigualdades étnico-raciais e o racismo institucional ${ }^{5}$ como determinantes sociais das condições de saúde" (Brasil, 2010a, p. 37), sendo a população negra exposta a altas taxas de adoecimento, morbidade e mortalidade (WERNECK, 2010). Visando "promover a

\footnotetext{
${ }^{4}$ Ver mais informações em: <http://www.cremeb.org.br/index.php/noticias/usuarios-do-sus-terao-queinformar-raca-e-cor-em-formularios-de-saude/>. $\quad$ Acesso
em:<https://nacoesunidas.org/quase-80-da-populacao-brasileira-que-depende-do-sus-se-autodeclaranegra/> Acesso em: jan. 2018.

${ }^{5} \mathrm{O}$ racismo institucional é definido pelo "fracasso das instituições e organizações em prover um serviço profissional e adequado às pessoas devido a sua cor, cultura, origem racial ou étnica” (DFID \& CRI, 2007, p. 2).
} 
saúde integral da população negra", o combate ao racismo e à discriminação nas instituições e serviços do SUS" (BRASIL, 2010a, p. 38), a referida Política Nacional indicou a atenção à coleta do quesito raça/cor como uma de suas estratégias.

Consideramos que a PNSIPN e o quesito raça/cor são proposições centrais para a intervenção nas iniquidades raciais em saúde, quando são não apenas reconhecidas, mas, sobretudo, trabalhadas. Isto é, quando a coleta deixa de ser uma ação burocrática das recepções dos equipamentos de saúde, adentrando as salas de atendimento, povoando o raciocínio clínico das equipes e os processos de gestão.

As pesquisadoras Santos e Santos (2013) analisaram narrativas dos(as) profissionais da atenção básica acerca da aplicação da PNSIPN no dia a dia dos serviços. Elas encontraram interpretações que evidenciam resistência e desconhecimento: "ficou evidente que o profissional tende a não perceber a discriminação ou a insistir em sua inexistência, contribuindo, assim, para a inação do sistema frente à discriminação e, consequentemente, para sua manutenção e ampliação" (Santos \& Santos, 2013, p. 568-569), além de entenderem a PNSIPN como “desnecessária e promotora da discriminação" (SANTOS \& SANTOS, 2013, p.568569).

Os profissionais de saúde acabam reproduzindo as relações raciais hierarquizadas, construídas ao longo de centenas de anos, associando cor da pele à posição hierárquica inferior, ao baixo poder aquisitivo e distinguindo condutas de cuidado entre as populações negra e branca. As pesquisadoras (KALCKMANN et al., 2007) indicam que esse fenômeno não é exclusividade dos equipamentos de saúde pública, incluindo planos de saúde diversos. Além disto, resultam no desinvestimento em saúde da população negra, que passa a desacreditar do cuidado oferecido, além de não se identificar com as propostas clínicas, o que, por sua vez, não colabora com um processo de identidade racial e subjetiva (KALCKMANN et al., 2007).

Para Batista e Barros (2017, p. 2), “a PNSIPN dá certo quando há compromisso de gestores(as) e técnicos(as), quando há uma efetiva coordenação do programa e quando o movimento social apoia a gestão". Os mesmos autores ponderam, porém, que a política é recente, tem pouco mais de uma década; além disto, vige um desconhecimento dos(as) trabalhadores(as) do SUS e da sociedade civil, como um todo, 
a respeito do racismo e seus possíveis efeitos na saúde, bem como no acesso aos serviços, na manutenção das(os) usuárias(os) nos mesmos e na qualidade do cuidado.

O quesito raça/cor é uma ferramenta que permite a mensuração e a apresentação dessas iniquidades, bem como dos impactos das diferentes condições de acesso e de cuidado em saúde para as diferentes raças. Acredita-se que os subsídios oferecidos - por meio da análise dos dados gerados pela coleta desse quesito, tanto na formulação de projetos terapêuticos singulares, como na de políticas públicas em saúde - podem ser um gatilho para ofertas de cuidado com equidade racial.

A incorporação dessa legislação, alimentando os sistemas de informação no âmbito da saúde, permite evidenciar "diferenças raciais e vulnerabilidades produzidas no processo saúde-doença. Conhecer os perfis de morbimortalidade da população brasileira no que tange à autodeclaração étnico-racial permite subsidiar a objetivação de políticas (...) à superação de iniquidades” (SOARES, 2012, p. 36).

Para Osório (2003), o quesito raça-cor, embora tenha recebido muitas críticas ao longo do tempo, é a melhor ferramenta para identificar os grupos raciais do Brasil uma vez que a imensa maioria das pessoas, em território nacional, são contempladas em algumas das cinco opções de cor/raça que o Instituto Brasileiro de Geografia e Estatística (IBGE) emprega: preto; pardo; ${ }^{6}$ branco; amarelo; ou alguma etnia indígena. Contudo, quando o quesito cor é negligenciado (não coletado ou coletado de maneira equivocada, com a heteroclassificação), gera não apenas dificuldades na criação de políticas públicas, mas perde também seu potencial de análise do dia a dia dos equipamentos.

Dias, Giovanetti e Santos (2009) asseveram que, para quebrar as resistências em relação à coleta, faz-se necessário reconhecer que há racismo, que ele afeta os profissionais e os equipamentos de saúde; faz-se necessário também compreendê-lo e, por último, assumir o compromisso de trabalhá-lo em uma lógica antirracista. O relato de Andréa Santos Rafael (2003, p. 31), médica infectologista, demonstra a potencialidade desse processo: "foi um longo processo de discussão envolvendo toda a equipe (...). Revimos nossos conceitos e sentimentos em relação ao racismo (...) para perguntar mais tranquilamente aos usuários a qual cor/raça eles pertenciam”. Contudo, o

\footnotetext{
${ }^{6} \mathrm{~A}$ junção das pessoas que se autodeclaram da cor preto ou pardo compõem aqueles que se identificam racialmente como negros (as).
} 
relato da profissional de saúde permite ver outra dimensão: quando feita com uma intenção analítica, ela se sobrepõe à coleta, podendo se tornar uma demanda de cuidado no atendimento/acolhimento/PTS, além de transformar trabalhadores e equipes de saúde.

No entanto, de outro lado, é importante problematizar tanto os riscos da idealização da coleta do quesito como a estratégia central para a construção da equidade (uma vez que essa ação não modifica por si só as relações de poder presentes no racismo), quanto a suposição de que tal indicador é condição para essa construção ou para que a atenção em saúde não produza iniquidades e racismo.

Desse modo, pesquisadores das teorias étnico-raciais, como Piza e Rosemberg (2002), reconheciam os paradoxos e as contradições existentes nas coletas e em suas ferramentas; contudo, afirmavam a importância dos processos de identificação e as necessidades de aprimoramento das técnicas. "O que fazer diante de tanta ambiguidade, de tantos imponderáveis no processo de pertencimento/atribuição racial no Brasil? Abandonar o mapeamento das informações estatísticas com certeza não é a solução" (PIZA \& ROSEMBERG, 2002, p. 116). Acredita-se que a ampliação e a continuidade da discussão da coleta, nos diversos âmbitos das políticas públicas, entre eles, segurança, saúde, assistência social e educação, irá colaborar para um melhor entendimento dos "limites de segurança necessários na apreciação dos dados sobre a cor no Brasil e estimular a produção de estudos e pesquisas sobre as dimensões antropológicas e psicossociais no processo brasileiro de auto e heteroatribuição de cor" (PIZA \& ROSEMBERG, 2002, p. 117).

Batista e Barros (2017), Bento (2005), Dias, Giovanetti e Santos (2009), Braz et al. (2013) e Faustino (2017) consideram que, para a população negra ser assistida no SUS com equidade, faz-se necessária a transversalização da temática étnico-racial nas três esferas de gestão do SUS (federal, estadual e municipal). Enquanto a saúde da população negra for tratada de modo periférico, sem a priorização por parte do governo em todas as esferas, a PNSIPN continuará ofuscada pela "cegueira institucional" (Lopes, 2005).

No plano micropolítico, por sua vez, as ações de formação em saúde e a análise permanente das práticas cotidianas nos serviços de saúde são outros campos fundamentais neste trabalho. Escutar os profissionais e gestores dos equipamentos de 
saúde que assistem majoritariamente à população negra é fundamental para a desinstitucionalização do racismo. A desnaturalização de conceitos impõe reflexão crítica; do contrário, as práticas de cuidado tendem a replicar e reforçar condições díspares, favorecendo alguns - os brancos - e desfavorecendo outros - os negros (CONSELHO FEDERAL DE PSICOLOGIA, 2017).

Veremos a seguir alguns desafios e dificuldades do CAPSij pesquisado neste tema.

\section{O AQUILOMBAR-SE NA ESFERA POLÍTICO-INSTITUCIONAL: DESAFIOS E PARADOXOS}

Do ponto de vista sociodemográfico, o CAPSij estudado tem a maioria de usuários autodeclarados negros, refletindo a realidade racial do território nacional, assim como do seu território de cobertura, localizado no extremo da Zona Norte do município de São Paulo, que também apresenta prevalência de população negra. ${ }^{7}$ Segundo Rolnik (1989), tal prevalência é herança do período, entre os anos 1980 e 1990, quando os(as) negros(as) foram concentrados nas periferias da região noroeste da cidade.

A equipe apresentava um quadro com relativa diversidade racial, todavia, quando observamos as ocupações/cargos, vemos que esta corresponde à estrutura empresarial brasileira, na qual não há equidade racial. Em sua totalidade, são 32 profissionais, que se autodeclaram: 19 brancos(as), 8 pretos(as), 4 pardos(as), 0 amarelo(a), 0 indígena e 1 do qual não se obteve a informação por causa de afastamento do profissional. No entanto, os(as) brancos(as), em sua maioria, estão nos postos de técnicos e na gerência. A maioria dos(as) negros(as) (somatória de pretos e pardos) ocupam cargos e funções de terceirizados e não técnicos. Observa-se que, em um equipamento no qual a presença de profissionais do sexo feminino é maciça (são 24 mulheres e 10 homens, no total), o cargo de gerência é ocupado por um homem.

A coleta do quesito raça/cor acontece, em geral, no preenchimento da ficha cadastral, na recepção pelo(a) auxiliar técnico(a)-administrativo(a) (ATA) ou na

\footnotetext{
7 Segundo o Censo Demográfico do Instituto Brasileiro de Geografia e Estatística (IBGE) (2010), a população negra da cidade de São Paulo vem aumentando. Atualmente, $37 \%$ da população se autodeclara preta e parda, sendo em números absolutos quantitativamente a maior população negra do Brasil.
}

Revista da ABPN • v. 12, n. Ed. Especial - Caderno Temático: "III ANPSINEP Articulação Nacional de Psicólogas/os Negras/os e Pesquisadoras/es” • outubro de 2020, p. 108-137 
continuidade do processo de acolhimento. Grandi, Giovanetti e Santos (2013, p. 595) sinalizam, entretanto, que raramente o recorte racial é feito nos atendimentos: "[há] maior incidência de conversa a respeito do tema no acolhimento. Durante as consultas, conversou-se, por vezes, com a população". Acompanhemos um fragmento de entrevista com a ATA, que nos aproximará da sua experiência de coleta do quesito raça/cor:

Pergunta: Como é que vocês, na recepção, lidam com a questão racial? O que é que vocês já perceberam?

Resposta: Nossa. Para mim é uma questão que eu não ponho foco. Então eu não sei te falar.

Pergunta: Vocês lidam com o quesito raça/cor?

Resposta: Sim. Quando a gente faz a ficha, a gente pergunta: "[De] qual cor que você acha que é?".

Pergunta: Como é que vocês perguntam?

Resposta: Eu pergunto assim: "Me fala uma coisa: [de] que cor que você acha que você é? Branco, preto, pardo, amarelo ou indígena?", e aí a pessoa fica meio na dúvida, fica naquela coisa assim, não sabe responder. (Então) falo: "olha, [se] você falar para mim que você é azul, é a cor que eu vou colocar aqui, o que você sente que é. Sempre questiono azul.

Pergunta: Para que é que serve esse quesito?

Resposta: Não sei, eu acho que é uma contagem, não é? Para estatística? Eu ouvi falar que era para isso. Não sei se é também a pessoa se sentir... bem, de verdade, né? ((acha graça)). Mais para estatística, eu penso.

Pergunta: Você considera que é importante para o CAPS essa informação?

Resposta: Eu acho útil, mas enfim. Então. Para nós é, porque eu nunca vi as pessoas com... se ela é branca, preta, para mim tanto faz. Para mim, a gente tem que ver a pessoa, então eu acho que é indiferente.

Eu acho que não tem necessidade nenhuma, mas... se vai tratar a pessoa diferente só porque ela é de outra cor, né? Então para mim parece isso quando tem essa informação, você precisa saber como a pessoa é, que cor que a pessoa é, para poder saber o jeito que você vai tratar. Não parece isso? Eu acho, eu sinto isso.

Pergunta: Você acha que a equipe leva em consideração essas questões raciais?

Resposta: Não. A equipe também não, vê como pessoas. Eu percebo isso.

Pergunta: Você acredita que olhar para as questões raciais é não ver como pessoa?

Resposta: ((silêncio)) É. Eu penso assim. Você vai olhar pela cor, ou pela... status financeiro, sabe assim? Eu acho que você começa a dividir as pessoas por... qualificar as pessoas, não?

Pergunta: Como é que você se sente quando você tem que perguntar para a pessoa o quesito raça/cor?

Resposta: Eu acho ridículo, eu não gosto. Mas eu tenho que fazer, entendeu? Porque às vezes está lá, "Não informado". Eu preciso perguntar porque a gente tem estatísticas e fechamento de produção, se aquele item estiver em branco, dá problema, dá inconsistência da minha produção. Então é só por uma questão de produção que a gente precisa saber disso. Não que eu precise, entendeu? É que a 
gente puxa relatórios e se não tiver essa informação, e se estiver em branco, vai dar erro no meu relatório. Por quê? Porque o sistema pede e não porque a gente queira saber. Não é uma coisa que faça diferença para a gente. Mas faz diferença para a produção.

Eu tenho vergonha de perguntar. Às vezes... quando chega nessa parte: "ah, vou ter que perguntar"... sabe aquela coisa, "vou ter que perguntar"?

Pergunta: Então, dá vergonha às vezes?

Resposta: Dá. Eu acho chatíssimo essa pergunta.

Pergunta: E você acha que as pessoas estão acostumadas a escutar essa pergunta?

Resposta: Eu acho que não. Eu acho que não. Na verdade deveriam, porque quando você vai fazer o cartão do SUS, você tem que colocar essa informação. Na maioria das vezes, não tem essa informação. Significa que o profissional não perguntou ou pôs aleatoriamente, deixou lá "não informado". Então as pessoas não estão acostumadas por isso, porque às vezes o cadastro não é completo. $\mathrm{E}$ aí, quando a pessoa vem fazer ficha, a gente sempre olha, e tenta atualizar o máximo de dados possíveis, e é uma coisa que a gente tem que perguntar (acha graça).

Ainda que orientada a realizar o procedimento, a ATA enfatiza mais sua função utilitária, de controle de dados para fins estatísticos, o que legitima a produção do serviço. Percebe que há outros elementos em jogo relativos ao cuidado, ou a um reconhecimento, a um se "sentir bem": "Não sei se é também a pessoa se sentir... bem, de verdade, né?", mas não tem muita certeza. Ou melhor, tem mais dúvidas.

Certamente, a apropriação crítica do objetivo do quesito é um elemento que precisa ser mais bem observado e trabalhado. Como aponta o documento Relações raciais: referências técnicas para a prática da(o) psicóloga(o), elaborado no âmbito do Centro de Referência Técnica em Psicologia e Políticas Públicas (CREPOP/CFP), de 2017: “As(os) profissionais podem não considerar relevante o preenchimento desse item, ou mesmo acreditar que podem ofender a(o) usuária(o) com a pergunta, em ambos os casos evitando fazer o questionamento" (CONSELHO FEDERAL DE PSICOLOGIA, 2017, p.117).

Quando a(o) profissional não está convicta(o) da importância do instrumento (quesito raça/cor) e/ou da política (PNSIPN), ela(e) muito possivelmente não cumprirá duas de suas funções, a saber, o serviço educativo e o político. Como apontam Grandi, Dias e Glimm (2013, p. 594), embora deva se incentivar a autodeclaração, segundo o que estabelece o IBGE, "é responsabilidade do trabalhador da saúde procurar esclarecer as dúvidas". Desse modo, é aberto o campo para a reflexão, inclusive quanto à implicação política do usuário: "há muitos desafios a serem enfrentados quando se

Revista da ABPN • v. 12, n. Ed. Especial - Caderno Temático: "III ANPSINEP Articulação Nacional de Psicólogas/os Negras/os e Pesquisadoras/es” • outubro de 2020, p. 108-137 
discute relações raciais, mas a experiência tem revelado que, de fato, esta é uma genuína experiência de formação política" (BENTO, 2002, p.149).

Coletar o quesito raça/cor pode ser entendido como o primeiro passo de uma conversa sobre relações raciais em um equipamento de saúde. É semelhante a quando se encontra alguém pela primeira vez e pergunta a ela: “Como vai?". Essa pergunta tem a intenção de quebrar o silêncio, "o gelo", e iniciar uma conversa que interesse. O aspecto racial no Brasil costuma estar nessa condição de congelamento: os profissionais e os usuários costumam evitá-lo. Como visto anteriormente, a entrevistada disse que faz a coleta do quesito raça/cor por obrigatoriedade ou, ainda, diz não "colocar foco nisso".

Esse segundo aspecto da posição da entrevistada, de "não colocar foco nisso", no entanto, merece atenção, pois é aqui que ela sustenta de modo muito vigoroso um conjunto de argumentos que aponta o risco da discriminação como um efeito mesmo do que se pretende combater, quando "a diferença é, ela mesma, um fazedor de diferença, um difference maker" (Pierucci, 2013, p. 129). Como aponta o mesmo autor: "A fixação do olhar na diferença pode terminar em fixação essencializante de uma diferença" (PIERUCCI, 2013, p. 127).

Esse saber prático da ATA, destacado pela fala "acho que você começa a dividir as pessoas por... qualificar as pessoas, não?”, nos aproxima de duas percepções:- dos efeitos da própria noção de raça, como uma construção social, que pode ser produtora de discriminação, na medida em que "qualifica" as pessoas; do risco das políticas que visam combater os efeitos do racismo produzirem, elas mesmas, práticas divisórias (FOUCAULT, 1995) e dificultarem a configuração do comum.

De fato, a paralisação cega nas identidades pode levar a novas segregações, fragmentações e distância social. Com Mbembe, pensamos que a direção ético-política do comum não abandona as diferenças: “o que teremos que imaginar será uma política do ser humano que seja fundamentalmente uma política do semelhante, mas num contexto onde, é verdade, o que partilhamos em conjunto sejam as diferenças" (MBEMBE, 2014, p. 297).

No entanto, não se pode deixar de pensar nos riscos de se repetir uma solução próxima à daquela construída historicamente no Brasil: o mito da democracia racial, pelo qual se forjou a hipótese de que no Brasil "o preconceito racial nunca fora forte o suficiente para criar uma 'linha de cor"' (GUIMARÃES, 2006, p. 269). 
Outra fala da ATA que nos interessa destacar é: “(...) se ela é branca, preta, para mim tanto faz. Tem que ver a pessoa, então eu acho que é indiferente. Acho que não tem necessidade nenhuma, vai tratar a pessoa diferente só porque ela é de outra cor, né?". Se os enunciados do "tanto faz" e do "indiferente" afirmam um certo lugar do humano como universal (universal como o lugar de acolhida de qualquer um) e abrem para uma ética do universal na saúde, não podem prescindir da discussão sobre a equidade racial no SUS. Como vimos acima, as condições de saúde não são as mesmas conforme as raças. Por isto, ao lado da universalidade (saúde para todos), é necessário afirmar a equidade (saúde sensível às características específicas da população).

As fichas de identificação que vão (cada vez mais) destacando particularidades, como sexo, idade, raça/cor, diagnóstico, entre outras, necessariamente impõem um exercício de diferenciação estigmatizante do particular? Como colher aspectos e informações que denotam a diferença sem produzir um engessamento nessa posição e, sem perder de vista a singularidade? Afinal, este é o objetivo do CAPS: a reinserção/inserção nos espaços comuns, no laço social, no universal. Contudo, trata-se de uma inserção/reinserção na qual caibam as particularidades, as diferenças e, acima de tudo, as singularidades.

É (inclusive) na esfera das singularidades que o profissional de saúde mental deve atuar, afinal a dimensão racial afeta as subjetividades dos indivíduos de todas as raças, assim, são nas relações raciais (por exemplo, no agir do cuidado em saúde), nos encontros entre iguais e distintas raças, que as singularidades operam e se transformam.

Apontamos que um cuidado em saúde mental se dá no encontro dos diversos sujeitos raciais, desde que haja possibilidade de acolhimento das distinções raciais sem hierarquização, ou melhor, um acolhimento com equidade racial.

Finalmente, cabe destacar a referência ao constrangimento. Quando a profissional diz que acha essa pergunta "chatíssima", "que acha ridículo" e "que sente vergonha de perguntar", ela expressa sentimentos comuns a muitos profissionais: "o tema pode provocar reações intensas e contraditórias (...) como dor, raiva, tristeza, sentimentos de impotência, culpa, agressividade e etc.” (BENTO, 2002, p. 148). Constrangimento é uma dimensão afetiva, um elemento que indica que há dimensões psicossociais que estão em jogo que não são respondidas pelas informações das "cartilhas" de combate ao racismo: as afetações que as relações raciais produzem 
precisam ser acolhidas em dispositivos de educação permanente nos serviços. Segundo Nogueira (1998, p. 8), não basta "a consciência da condição de negro, nem o engajamento em relação às lutas políticas contra a discriminação racial são suficientes para modificar a condição do negro, na medida em que os sentimentos do racismo inscritos na psique permaneçam não elaborados”.

Embora se vislumbre um período no qual as diferenças não se convertam em desigualdades, na contemporaneidade ainda se faz preciso exigir igualdade a partir das diferenças.

Enquanto persistir a ideia segundo a qual só se deve justiça aos seus e que existem raças e povos desiguais, e enquanto se continuar a fazer crer que a escravatura e o colonialismo foram grandes feitos da "civilização", a temática da reparação continuará a ser mobilizada pelas vítimas históricas da expansão e da brutalidade europeia no mundo (MBEMBE, 2014, p. 297).

Desse modo, raça, gênero, classe e faixa etária são dimensões que se interseccionam na experiência de vida dos usuários e dos profissionais e devem ser consideradas pelas equipes, sendo necessário que as instituições de saúde estejam atentas e em condições de analisar os efeitos das tecnologias que utilizam e que modulam as diferenças como desigualdades, como invisibilidade ou como variação permanente do vivo.

A primeira fala do gerente traz a importância de ampliar a visibilidade do tema no serviço. Quando o gerente olha para o serviço, percebe que a temática étnico-racial está como uma variável sombra no dia a dia do equipamento de saúde mental. Ele sinaliza a necessária sensibilidade que a equipe precisa construir, bem como a necessidade da inclusão do tema "como questão para o serviço e não apenas como problema que tem lugar a partir da demanda do usuário, ou melhor, quando um usuário ou profissional trouxer, de modo direto, o assunto". O gestor destaca ainda a riqueza que foi ter na equipe uma profissional que não apenas estava consciente da existência do racismo, mas propunha estratégias para trabalhar as questões que o racismo pode suscitar, convocando o restante da equipe para essa reflexão e atuação.

Pergunta: Tem algum caso ou situação que você pensa/lembre que dialoga com as questões raciais? 
A primeira coisa que eu penso não é nem tanto a partir de um caso, mas acho que talvez mais de uma situação, de um acontecimento, que foi a chegada da J., que foi a nossa oficineira.

A J. traz essa discussão muito firme desde que ela chega, acho que (...) pela história dela, de estar envolvida com movimentos de discussão de raça, etc., com uma pegada pela via da cultura, ela traz para a gente - não me lembro se foi no Dia da Consciência Negra, acho que foi - o movimento crespo, que além de ter uma pegada mais feminista, tinha essa coisa do cabelo crespo e tal e foi bem bacana. Isso na verdade suscita dentro da unidade, tanto na relação com os usuários, como principalmente na relação com a equipe, essa discussão sobre o racismo.

Então, essa chegada dela traz esse campo de visibilidade e de discussão para essa questão, que, acho que posso dizer muito tranquilamente, não permeia nosso cotidiano. Eu acho que esse é um assunto que, sim, entra em alguns casos, mas quando isso é trazido ou verbalizado diretamente pelos usuários. $\mathrm{Eu}$ não acho que a gente tem um debruçar-se sobre essa questão, não, pelo menos na intensidade que o tema merecia.

(...) Quando ela trouxe lá o movimento crespo, eu lembro que teve uma situação, de embate entre algumas pessoas da equipe que foi bem difícil, bem tenso, isso reverberou acho que pelo menos mais uma semana, aquele clima pesado, dava para cortar com a faca de tão pesado que ficou. As pessoas foram dizendo o que entendiam como preconceito, como racismo (...).

No período que a J. esteve aqui, sim, acho que ela traz isso muito mais vivo, por trazer essa discussão de outras [formas], seja da contação de histórias, que não são histórias tradicionalmente conhecidas, vamos dizer assim, mas que tem aí uma pegada mais afro e tal. Acho que então para poder falar desse campo de cultura, acho que ela vai trazendo essa discussão (...). Mas acho que é isso, nessa situação específica, pelo menos quando isso acontece, dá visibilidade e divisibilidade para isso, e aí, isso por um tempo reverbera e vem para a discussão de equipe, ela traz e apresenta algumas coisas, mas acho que depois da saída dela, meio que naturalize ou minimalize essa história. Essa discussão aparece declarado, não acho que a gente tenha ainda incorporado a sensibilidade que a gente precisava ter para esta questão. (Entrevista com o gerente, que se autodeclara branco).

A postura do gerente sinaliza para o que é chamado de "diagnóstico da discriminação institucional” (CONSELHO FEDERAL DE PSICOLOGIA, 2017), uma vez que reconhece o insuficiente conhecimento da temática racial pelo serviço. Tal capacidade de autoavaliação de um serviço para a construção de uma postura antirracista implica: olhar para o histórico da instituição, ponderar se em algum momento as relações raciais foram trabalhadas; analisar como a instituição lida com as pessoas atendidas dentro das suas especificidades raciais; se a equipe tem em seu quadro diversidade racial; se o Projeto Terapêutico Institucional contempla a perspectiva racial; se existem materiais de publicidade, comunicação e formação que contemplam as diversas raças; se o orçamento da instituição considera e inclui as 
diversidades raciais; ou se os materiais específicos de trabalho (no caso do CAPSij, jogos, bonecas(os), revistas, filmes, gizes de cera, lápis de cor, livros e fantasias) contemplam a raça negra; o levantamento de práticas do equipamento com o território e a comunidade; se o trabalho intersetorial e de rede buscam instituições que fazem o recorte racial; a investigação sobre a diversidade racial dos seus usuários e do território; e, por fim, se fornecedores em geral e as empresas que prestam serviços estão atentos e implicados com as questões raciais em seus quadros e produtos (CONSELHO FEDERAL DE PSICOLOGIA, 2017).

Em tal processo diagnóstico, é necessário ficar atento aos efeitos que produz: a equipe tem de lidar com a possibilidade do "clima pesado, que dá para cortar com uma faca", pois, como aponta Bento (2002, p. 148), as(os) profissionais, ao discutir o racismo, “esperam abordar uma opressão que 'está lá' na sociedade, e não em algo que as envolva diretamente, ou que envolva a instituição da qual fazem parte" e/ou "nem sempre estão desejosas de admitir que, se são brancas, em alguma instância são beneficiárias do racismo" .

O gerente chama a atenção, ainda, para a diferença entre demanda e encomenda, sinalizando que é tarefa do serviço tal trabalho mesmo que ele não apareça formalmente solicitado. Aponta também os limites da política no seu plano formal, insuficientes para que o trabalho seja incorporado de maneira efetiva pelas equipes.

Pergunta: Você acha que o território demanda o trabalho das relações raciais? ((silêncio)) Resposta: Acho que se pensar em termo de demanda, sim. Se pensar em termo de encomenda, não. Não tem um pedido para lidar com isso, eu nunca me lembro de ter ouvido de nenhuma instituição, escola, conselho tutelar, da agente de saúde, não me lembro disso ter aparecido como uma questão "vamos cuidar disso".

Pergunta: Essa encomenda, como você disse, não apareceu?

Resposta: A encomenda não aparece no sentido "precisamos lidar com isso". Agora que isso faz parte da demanda, sem dúvida. Por que é isso, isso atravessa um monte de instituição, só não falamos disso, aí você precisa de ferramentas para lidar. Não sei se isso é banalizado ou naturalizado. "Não, isso não é uma questão para a gente", quando na verdade é uma puta de uma questão. Eu acho que é mais banalizada essa questão do que naturalizada, no sentido de incorporada.

Comentário do pesquisador: Sim.

Resposta: Acho que aparecem outras questões de outras minorias, da mulher, do LGBT, acho que até dos sul-americanos, tem aqui inúmeras reuniões de gerentes e de discussão de território. Aparece muito, que é a história dos bolivianos, que isso é uma puta de uma questão também para o território, mas 
da população negra, não lembro, para dizer que não teve absolutamente nada, participei nesses seis anos que eu estou aqui, acho que de duas conferências ou pré-conferências, não vou lembrar exatamente, que era da saúde da população negra, mas é isso, como um evento, acho que mais formal, um pouco mais nesse sentido, mas é isso.

Para pesquisadores(as) da temática étnico-racial, nos equipamentos de saúde "há uma tendência a minimizar as queixas" (Kalckmann et al., 2007, p. 151) da população negra. Quando o gerente relata que não existe uma "encomenda" do território e reconhece uma banalização e/ou naturalização da invisibilidade da saúde da população negra, que acaba sendo presença formal apenas em datas específicas como o Dia da Consciência Negra ou nas (pré) conferências de saúde, reconhece o ensurdecimento da voz do território e dos usuários do equipamento, fruto do racismo institucional que estrutura as organizações brasileiras.

De outro lado, se forem escutadas as vozes dos usuários que querem falar do racismo, observa-se a relevância desse tema para essas pessoas. É o que observamos na atividade terapêutica que os profissionais do CAPSij fizeram, quando perguntaram para os adolescentes quais os temas que eles gostariam de abordar nas convivências e o primeiro da lista foi racismo, seguido por música, sexo, maus-tratos aos animais, feminismo, família, aborto, educação, crise de ansiedade e ilusão.

Camargo et al. (2012) nos auxilia a pensar a reação dos adolescentes negros e dos territórios negros periféricos, que costumam ser classificados como perigosos, violentos e agressivos. Todavia, esse ataque, ameaça e violência, enquanto uma tentativa de se fazer respeitar, seriam uma reação à invisibilidade do Estado, à naturalização e à banalização que o gerente relata. É necessário tomar a suposta violência desses territórios, crianças e adolescentes como um pedido de reconhecimento de suas potencialidades e de sua existência.

(...) o racismo, por conta de sua força ideológica e cultural, incita um duplo processo de exclusão social da população negra, posto que promove um extermínio identificatório, principalmente da criança e do adolescente negro que não quer se reconhecer como tal, e da sociedade que não o reconhece como sujeito de potencialidades. Semeado cotidianamente, o racismo, em sua invisibilidade, pode produzir transformações de ordem psicológica e social na vida desses indivíduos, colocando-os constantemente em estado de alerta, com medo de ser atacado, violentado, discriminado, mas muitas vezes também 
atacando, ameaçando, violentando, na tentativa de impor limites e se fazer respeitar (CAMARGO et al., 2012, p. 352).

Considera-se que o racismo, suas formas de humilhação e seus possíveis efeitos psicossociais sempre foram demandas de cuidado da população negra e que equipamentos de saúde como os CAPS são serviços potentes para esse cuidado, em razão de seu projeto ético-político. Contudo, quando esses equipamentos não se apropriam da temática étnico-racial podem entrar em contradição, constituindo-se "políticas que governam para vida, mas que também governam para a morte quando permitem a não implementação e a violação dos direitos desses sujeitos" (Scisleski et. al. 2016, p. 92).

As equipes dos CAPS, quando atentas às dimensões étnico-raciais, reconhecem os territórios como racializados (David \& Silva, 2018), fomentando intervenções terapêuticas que privilegiam o território como espaço de

convívio entre diferentes, de realização de trocas simbólicas e culturais, enfim, lugares e práticas que desconstroem, em seu fazer cotidiano, uma arraigada cultura de exclusão, invalidação e silenciamento dos ditos loucos, ao promover intervenções no território que revelam possibilidades de encontro, geram conexões, questionam os preconceitos e fazem aparecer a novidade: a presença cidadã dos portadores de sofrimento mental (CONSELHO FEDERAL DE PSICOLOGIA, 2013, p. 93).

Essa presença cidadã historicamente foi garantida no SUS nas instâncias de controle social. A participação dos usuários dos serviços substitutivos dos hospitais psiquiátricos, somada às vozes dos movimentos negros, nos conselhos e conferências de saúde, pode conectar duas vozes comumente ensurdecidas, a dos "loucos(as)" e a dos pretos(as). O fortalecimento dos temas "reforma psiquiátrica" e "saúde da população negra", nos planos estaduais e municipais de saúde, contribui para a redução das vulnerabilidades e para a desconstrução de estigmas e preconceitos no âmbito do SUS.

Pergunta: Nas (pré)conferências de saúde, a saúde mental da população negra foi pautada? Se foi, como?

Resposta: Sim. Em alguns momentos, sim. Eu lembro que em todas elas a gente sempre colocou alguma coisa, ainda que fosse no sentido de chamar a atenção para a saúde mental da população negra, de que jeito, como, nós não sabemos ainda, mas de poder... de cavar um espaço ali para falar disso. Então sim, nos relatórios finais têm, pelo menos nessas duas que eu participei, eu lembro que 
teve. Mas é isso, aparece no Dia da Consciência Negra. Então, repensando agora o encaminhamento das demandas, anualmente tem, a secretaria faz a Semana da Consciência Negra e tem a solicitação para todas as unidades fazerem alguma coisa.

O gerente relata que os trabalhadores do CAPSij não deixaram de marcar a necessidade de pautar a saúde mental da população negra em todas as (pré)conferências “como, nós não sabemos ainda mas, poder cavar um espaço ali para falar disso (...)". Assim, esse equipamento demonstra estar ancorado em uma ética antimanicomial e libertária, posição que fica ainda mais evidente quando a gerência reconhece as limitações do equipamento.

O entendimento que equidade racial é pauta urgente para a reforma psiquiátrica brasileira e para o SUS aos poucos tem crescido nos fóruns da luta antimanicomial. Exemplo desse reconhecimento é o parágrafo da recente Carta de Bauru - 30 anos, datada de dezembro de 2017 e redigida por diversos representantes da reforma psiquiátrica (membros da sociedade civil, usuários dos equipamentos substitutivos de hospitais psiquiátricos do SUS, trabalhadores, docentes, estudantes, pesquisadores, gestores, entre outros), que diz:

Não podemos deixar de frisar o avanço do conservadorismo e da criminalização dos movimentos sociais, defendemos a diversidade sexual e de gênero, as pautas feministas, a igualdade racial. Somos radicalmente contra o genocídio e a criminalização da juventude negra, a redução da maioridade penal, a intolerância religiosa e todas as formas de manicômio, que seguem oprimindo e aprisionando sujeitos e subjetividades. Apontamos a necessidade urgente de articulação da Luta Antimanicomial com os movimentos feministas, negro, LGBTTQI, movimento da população de rua, por trabalho, moradia, indígena entre outros, a fim de construirmos lutas conjuntas (BAURU, 2017, s.p.).

Esse movimento reconhece que o racismo compõe as lógicas manicomiais. Sabe-se que crianças, mulheres, população LGBTTQI, população de rua, indígenas e negros costumam ser os alvos das lógicas manicomiais e neomanicomiais: da segurança pública, militarizada, responsável por violências e mortes da população preta, em sua maior parte, jovens, homens e pobres, da medicina psiquiátrica com contemporâneos diagnósticos que rotulam crianças e adolescentes em situação de vulnerabilidade social, em sua maior parte, negros periféricos. 
Em resposta à neomanicomialização, precisamos lembrar que um dos primeiros territórios do Brasil a acolher os ditos revoltos, escravos, fugitivos, selvagens, perigosos, anormais, loucos, prostitutas(os) e alcoólatras, entre outros indesejáveis, foram os quilombos "grupos étnico-raciais negros dotados de relações territoriais específicas e caracterizados pela resistência à opressão histórica sofrida" (COSTA \& SCARCELLI, 2016, p. 1) com princípios já reformistas (para a época e para a contemporaneidade), que visavam (e ainda visam) liberdade, luta, emancipação, dignidade humana, direitos culturais, demarcações de terra para moradia, entre outros princípios igualitários e de cidadania; "a vinculação do conceito de quilombo com a noção de resistência mantém-se. Resistência relacionada ao trabalho familiar na terra e à sustentação da vida comum" (COSTA, 2018, p. 223).

Conforme o gerente alerta em seu relato, os equipamentos de saúde (em geral), naturalizam ou banalizam as iniquidades raciais, desconhecem as demandas de saúde da população negra, não estão apropriados da PNSIPN e de conceitos fundamentais para o cuidado em saúde mental da população negra. Ao final da entrevista, o gerente foi convidado para a reflexão sobre o lugar do branco nas relações raciais.

Pergunta: As relações raciais são uma questão para os brancos?

Resposta: Acho que os dois, acho que é isso. Tivemos pessoas que chegaram aqui porque foram vítimas do racismo, mas apareceu também, poucas situações aqui dentro, "não quero ficar no espaço coletivo porque tem uma pessoa negra comigo, nesse mesmo espaço". Então acho que aparece isso para os dois, para os dois lados (Entrevista com o gerente, que se autodeclara branco).

A lembrança do gerente explicita o imaginário social de superioridade da branquitude, isto é, do poder de classificar e discriminar os outros como não brancos, exercendo privilégios simbólicos e materiais (MÜLLER \& CARDOSO, 2017). Segundo ele, um usuário diz "não quero ficar no espaço coletivo porque tem uma pessoa negra comigo, nesse mesmo espaço”. Essa hierarquia racial, que oferece ao branco o topo, não é prerrogativa de adultos; a grande maioria das crianças vive em espaços onde o ideal da brancura restringe de maneira exclusiva as "culturas infantis e elenca um conjunto de elementos - como a negação da história e da cultura africana, a escassez de brinquedos que representam os negros, a valorização de uma estética eurocêntrica -, enquanto 
forma pela qual a branquitude institui-se como norma" (CARDOSO \& DIAS, 2017, p. $303)$.

O que as instituições podem fazer para intervir sobre esse cenário? Para Bento (2002), as instituições podem/devem abordar alguns pontos, desde o início: (1) reconhecer que o racismo afeta brancos e negros de modo problemático, todavia o impacto para cada grupo racial é distinto; (2) quando as pessoas adquirem uma perspectiva crítica sobre o racismo e seu funcionamento, elas devem se implicar com a quebra desse ciclo, tentando reconhecer, interromper e mudar seu comportamento, deixando de responsabilizar (apenas) a família, a escola, as mídias, em uma conduta projetiva; (3) posicionar-se buscando mudança, dando exemplos e enfatizando as posturas antirracistas, individualmente e institucionalmente, mesmo sabendo que essa mudança ocorrerá em um processo de longo prazo. Como o próprio gerente disse, essa é uma questão "para os dois lados".

Porém, o branco não costuma perceber sua brancura, o que dificulta a análise e a intervenção. Para Schucman (2014), a maneira que a brancura pode se desassociar da branquitude passa pelo reconhecimento, pela aquisição da consciência dos privilégios, pelo entendimento da estrutura social racista e pela negociação de sua branquitude. Isso deve acontecer na própria identidade racial branca, na construção de novos sentidos do que é ser branco, em uma desvinculação de brancura da branquitude. Finalmente, na conclusão da entrevista, o gerente foi convidado para a reflexão sobre o racismo institucional.

Pergunta: Você, enquanto gestor, já pensou na questão do racismo institucional. Nunca pensou? Gostaria de pensar?

Resposta: Como estava dizendo desde o começo da conversa, não me orgulho disso, mas é um assunto no qual eu não manejo os conceitos, não círculo bem. Deveria? Acho que sim, me dedicar mais a isso, mas não tenho, é isso, não tenho esse registro do interior, assim de já ter pensado e discutido isso, e acho que isso vai talvez compondo algumas sutilezas do dia a dia, das relações, acho que das relações pessoais de trabalho e tal, mas enquanto uma questão institucional gostaria muito de poder, conforme a gente vai falando aqui, vou até pensando, sentindo mais o peso desse débito que eu tenho, essa dívida que eu tenho. Talvez essa como outras tantas questões, não foram priorizadas na minha vida, na minha história aqui não, é isso. Não me orgulho nenhum pouco disso, mas é isso. 
O gerente reconhece que raça vai "compondo as sutilezas do dia a dia, das relações", mas que seu trato institucional ainda é insuficiente, ou, ainda, é um "débito". Para isso, a ampliação de ferramentas conceituais e analíticas seria importante: "talvez essa como outras tantas questões (...) não foram priorizadas na minha vida, na minha história, é isso. Não me orgulho nem um pouco disso, mas é isso". O fato de o gerente entender que a sensibilidade para perceber a presença da temática racial nas relações micro e macropolíticas é fundamental pode contribuir com a análise e a transformação do racismo institucional no serviço e no território de inserção do serviço, bem como estimular sua equipe a "contribuir na busca de saídas mais efetivas para a erradicação dos efeitos do racismo na saúde mental" (SILVA, 2004, p. 222).

Por fim, cabe destacar outras ações que podem ter grande potência de intervenção clínico-institucional, como as já referidas pelo gestor e equipe, como o caso da presença da oficineira no CAPSij e do Manifesto Crespo: as ações socioculturais. Os CAPS, desde seu surgimento, utilizam intervenções socioculturais, como "trabalhos orientados por princípios como emancipação, autonomia, consciência crítica, dentre outros que não sejam reduzidos ao caráter terapêutico" (AMARANTE, 2007, p. 76).

$\mathrm{Na}$ experiência de Abdias do Nascimento, no Teatro Experimental do Negro, fundado em 1944, encontra-se a tentativa de combater o genocídio do negro brasileiro: processo de um racismo mascarado (2017). Nascimento valorizava a potencialidade do rebelar-se juvenil como possibilidade de trabalhar os sentimentos de frustração decorrentes do racismo e também como possibilidade de identificação racial, de transformação e produção de vida: "a juventude negra canaliza suas ansiedades (...) utilizando a música, a dança, o vestuário, o corte de cabelo e outros símbolos como demonstrativos de inconformismo e confrontação" (NASCIMENTO, 2017, p. 164). Tal coincidência na direção ético-política entre a experiência de Nascimento e a aposta dos CAPSij na emancipação e na autonomia configura um vetor de intervenção que tem potência de combate ao genocídio do jovem negro brasileiro. Do mesmo modo, sugere a campanha "O SUS está de braços abertos para a saúde da população negra" (2017), que objetiva a "inclusão de práticas culturais afro-brasileiras, como capoeira, samba, maracatu, jongo, tambor de crioula, hip-hop, entre outras, manifestações ancestrais e contemporâneas de artes negras, nos programas de promoção da saúde" (BRASIL, 2017, p. 27). 
Aquilombar-se, enquanto princípio, é resistir em busca libertária, abolicionista e antirracista, valorizando os aspectos territoriais e culturais da população que predominantemente tem sido vitimada à lógica manicomial: a população negra. Esta é vítima diuturna de um estado que busca lhe fazer anônima, indigente, presa, morta e medicalizada. ${ }^{8}$ Para que a escuta e as práticas de cuidado do CAPSij contemplem a população negra, é necessário ter ciência do quantitativo de população negra do(s) território(s) e saber sua condição de vida; articulação de rede intersetorial visando as necessidades da população negra, seguindo a lógica da clínica ampliada $;{ }^{9}$ conhecer e saber intervir nas doenças prevalentes na população negra; priorizar jovens e mulheres negras, já que estes são os grupos mais vulneráveis perante o racismo de Estado (mulheres negras, em geral, são vítimas da mortalidade materna ${ }^{10} \mathrm{e}$ os jovens negros(as) são vítimas de homicídios); promover cultura de paz e não violência racializada; promover gestão estratégica e participativa, que inclua ações voltadas à saúde da população negra nos Planos Anuais de Saúde; fortalecer as instâncias de controle social do SUS (convocando os movimentos negros); e implementar os comitês de saúde da população negra; por último, exigir educação permanente, com a inclusão de temas de saúde da população negra e racismo (BRASIL, 2017). Essas ações iriam compor uma ética aquilombada na RAPS, manteria vivas as tradições culturais e religiosas da população negra, com a altivez das ancestralidades negras, aportadas na resistência de opressões historicamente sofridas.

\section{CONSIDERAÇÕES FINAIS}

Este trabalho se assenta em estudos que evidenciam o vínculo entre loucura e população negra produzido em distintos cenários históricos e políticos. Tendo em vista

\footnotetext{
${ }^{8} \mathrm{~A}$ medicalização toma como princípio os modelos de saúde orgânicos para designar a esfera psíquica, produzindo a psicopatologização da vida cotidiana.

9“'A clínica ampliada considera fundamental ampliar o 'objeto de trabalho' da clínica. (...) A ampliação mais importante, contudo, seria a consideração de que, em concreto, não há problema de saúde ou doença sem que estejam encarnadas em sujeitos, em pessoas" (CAMPOS \& AMARAL, 2007, p. 852).

10“'Analisando a base de dados do Comitê de São Paulo, Martins encontrou maior razão de mortalidade materna para as mulheres pretas, atingindo 562,35/100 mil nascidos vivos, com risco relativo de 6,7. A razão total foi 56,15/100 mil nascidos vivos. (...) Entretanto, as mulheres pretas apresentam maior razão de mortalidade materna em São Paulo" (MARTINS, 2006, p. 2476).
} 
que o racismo, enquanto relação de poder e sustentação de privilégios, produz subjetividades, podendo gerar sofrimento psíquico, afirma-se que os aspectos étnicoraciais não devem mais configurar-se como variáveis sombra nos cuidados de saúde/saúde mental (ROSA \& CAMPOS, 2012).

Tal cuidado poderia estar endereçado nas seguintes perguntas: A reforma psiquiátrica brasileira está disposta a perguntar: qual é (ou tem sido) a sua raça/cor? Qual a singularidade dos sofrimentos psíquicos identificados na população negra? Como reconhecer e transformar as heranças coloniais nas práticas de cuidado e nos "saberes" em saúde mental contemporâneos?

Considera-se que os avanços das políticas de saúde/saúde mental ancoradas na luta antimanicomial e nas reformas sanitária e psiquiátrica já trazem uma série de elementos capazes de dar visibilidade e ferramentas de intervenção no tocante às demandas referentes à população negra (como visto com a noção de clínica ampliada e territorialização, por exemplo). No entanto, considera-se também ser de fundamental importância um olhar singular para as demandas da população negra, como indica a PNSIPN.

Para isso propomos o aquilombamento dos CAPS como uma direção éticopolítica e como mutação subjetiva que põe em jogo um devir negro. Devir negro é aqui entendido na acepção que lhe dá Mbembe (2014, p. 296), como "possibilidade de construção de uma consciência comum do Mundo" que ganha na contemporaneidade uma maior força em função do "caráter descartável e solúvel da humanidade no neoliberalismo" (MBEMBE, 2014, p. 18). Assim como a luta antimanicomial propôs abandonar os paradigmas da saúde/doença, normal/anormal, sanidade/loucura, aquilombar-se é sair do paradigma racista, trabalhando pela desinstitucionalização do racismo como relação de poder. Tal processo põe em jogo, como colocou em relação à loucura, duas ações: sustentar o desejo da diferença, mas trabalhar também pela produção do comum.

Como sugere Mbembe (2014, p. 296), “o caminho passa pela produção, a partir da crítica do passado, de um futuro indissociável de uma certa ideia de justiça, da dignidade e do em comum", que exige políticas de justiça, de equidade, de restituição e de reparação. Estas são políticas que afirmam as utopias das lutas abolicionistas e das potentes e transformadoras revoltas negras. 


\section{REFERÊNCIAS BIBLIOGRÁFICAS}

ALMEIDA, Silvio Luiz de. O que é racismo estrutural?. Belo Horizonte: Letramento: 2018.

AMARANTE, Paulo. Saúde mental e atenção psicossocial. Rio de Janeiro: FIOCRUZ: 2007.

BATISTA, Luís. Eduardo e BARROS, Sônia. Enfrentando o racismo nos serviços de saúde. Cadernos de Saúde Pública, n.33, supl. 1, 2017, p. 1-5.

BARROS, Sônia. et al. Censo psicossocial dos moradores em hospitais psiquiátricos do estado de São Paulo: um olhar sob a perspectiva racial. Saúde e Sociedade, São Paulo, v. 23, n. 4, 2014, p. 1235-1247.

BAURU. Carta de Bauru - 30 anos. In: Encontro de Bauru: 30 anos por uma sociedade sem manicômios, 8-9 dez. 2017.

BENTO, Maria Aparecida da Silva. Branqueamento e branquitude no Brasil. In: CARONE, Iraí e BENTO, Maria Aparecida da Silva (Orgs.). Psicologia social do racismo: estudos sobre a branquitude e branqueamento no Brasil. Rio de Janeiro: Vozes, 2002.

BENTO, Maria Aparecida da Silva. A implementação do quesito cor na área da saúde: o caso da prefeitura de São Paulo. In: BATISTA, Luís Eduardo e KALCKMANN, Suzana (Orgs.) Seminário Saúde da População Negra Estado de São Paulo 2004. São Paulo: Instituto de Saúde, 2005.

BRASIL. [Política Nacional de Saúde Integral da População Negra (2010)]. Ministério da Saúde. Secretaria de Gestão Estratégica e Participativa. Departamento de Apoio à Gestão Participativa. Política Nacional de Saúde Integral da População Negra - Uma política do SUS. Brasília: Ministério da Saúde. 2010a. 36 p.

BRASIL. [Estatuto da Igualdade Racial (2010)]. Lei no 12.288, de 20 de julho de 2010. Institui o Estatuto da Igualdade Racial; altera as Leis nos 7.716, de 5 de janeiro de 1989, 9.029, de 13 de abril de 1995, 7.347, de 24 de julho de 1985, e 10.778, de 24 de novembro de 2003. 2010b.

BRASIL. Ministério do Planejamento, Orçamento e Gestão. Instituto Brasileiro de Geografia e Estatística (IBGE). Diretoria de Pesquisas. Coordenação de População e Indicadores Sociais. Estudos e Análises. Informação Demográfica e Socioeconômica. Características étnico-raciais da população - Classificações e identidades. Rio de Janeiro. 2013.

BRASIL. Ministério da Saúde, Secretaria de Atenção à Saúde, Departamento de Atenção Especializada e Temática. Centros de Atenção Psicossocial e Unidades de Acolhimento como lugares da atenção psicossocial nos territórios: orientações para elaboração de projetos de construção, reforma e ampliação de CAPS e de UA. Brasília: Ministério da Saúde, 2015.

BRASIL. [Material da campanha (2017)]. Ministério da Saúde. Secretaria de Gestão Estratégica e Participativa. Departamento de Apoio à Gestão Participativa e ao Controle Social. O SUS está de braços abertos para a saúde da população negra. Brasília, 2017.

Revista da ABPN • v. 12, n. Ed. Especial - Caderno Temático: "III ANPSINEP Articulação Nacional de Psicólogas/os Negras/os e Pesquisadoras/es” • outubro de 2020, p. 108-137 
BRASIL. Ministério da Saúde. Secretaria de Gestão Estratégica e Participativa. Departamento de Articulação Interfederativa. Painel de Indicadores do SUS, v. 7, n. 10. Temático Saúde da População Negra/Ministério da Saúde, Secretaria de Gestão Estratégica e Participativa, Departamento de Articulação Interfederativa. Brasília: Ministério da Saúde, 2016.

BRAZ, Rui Moreira et al. Avaliação da completude da variável raça/cor nos sistemas nacionais de informação em saúde para aferição da equidade étnico-racial em indicadores usados pelo Índice de Desempenho do Sistema Único de Saúde. Saúde em Debate, Rio de Janeiro, v. 37, n. 99,2013 , p. 554-562.

CAMARGO, Climene Laura de et. al. Reflexões sobre a violência vivenciada por crianças $e$ adolescentes negros. In: BATISTA, Luís Eduardo; WERNECK, Jurema e LOPES, Fernanda (Orgs.). Saúde da população negra. Brasília: Associação Brasileira de Pesquisadores Negros (ABPN): 2012.

CAMPOS, Gastão Wagner de Souza e AMARAL, Maria Aparecida do. A clínica ampliada e compartilhada, a gestão democrática e redes de atenção como referenciais teóricooperacionais para a reforma do hospital. Revista Ciência \& Saúde Coletiva, Rio de Janeiro, v. 12 , n. 4, 2007, p. 849-859.

CARDOSO, Cintia e DIAS, Lucimar Rosa. Branquitude na produção acadêmica sobre desigualdades raciais na educação infantil: um levantamento bibliográfico. In: MÜLLER, Tânia Mara Pedroso e CARDOSO, Lourenço. Branquitude: estudos sobre a identidade branca no Brasil. Curitiba: Appris, 2017.

CONSELHO FEDERAL DE PSICOLOGIA (CFP). Relações raciais: Referências técnicas para atuação de psicólogas/os. Brasília: Conselho Federal de Psicologia, 2017.

COSTA, Eliane Silvia. Quilombos ontem e hoje. In. SILVA, Maria Lúcia; FARIAS, Marcio; OCARIZ, Maria Cristina e STIEL NETO, Augusto Stiel (Org.). Violência e sociedade: O racismo como estruturante da sociedade e da subjetividade do povo brasileiro. São Paulo: Escuta, 2018.

COSTA, Eliane Silvia e SCARCELLI, Ianni Regia. Psicologia, política pública para a população quilombola e racismo. Revista de Psicologia da USP (online), v. 27, n. 2, 2016, p. 357-366.

DAVID, Emiliano de Camargo. Saúde mental e racismo: a atuação de um Centro de Atenção Psicossocial II Infantojuvenil. Dissertação (Mestrado em Psicologia Social). Pontifícia Universidade Católica de São Paulo PUC-SP, São Paulo, SP, 2018.

DAVID, Emiliano de Camargo e SILVA, Lidiane. Aparecida de Araujo. Territórios racializados: a Rede de Atenção Psicossocial e a Política Nacional de Saúde Integral da população negra. In. SILVA, Maria Lúcia; FARIAS, Marcio; OCARIZ, Maria Cristina e STIEL NETO, Augusto Stiel (Org.). Violência e sociedade: O racismo como estruturante da sociedade e da subjetividade do povo brasileiro. São Paulo: Escuta, 2018.

DESENVOLVIMENTO INTERNACIONAL E REDUÇÃO DA POBREZA (DFID) $\mathrm{e}$ COMBATE AO RACISMO INSTITUCIONAL (CRI). Combate ao racismo institucional. Brasília: 2007.

Revista da ABPN • v. 12, n. Ed. Especial - Caderno Temático: "III ANPSINEP Articulação Nacional de Psicólogas/os Negras/os e Pesquisadoras/es” • outubro de 2020, p. 108-137 
DIAS, Jussara; GIOVANETTI, Márcia R. e SANTOS, Naila Janilde Seabra. Perguntar não ofende. Qual é a sua cor ou raçaletnia? Responder ajuda a prevenir. Brasil, Centro de Referência e Treinamento DST/Aids. São Paulo: 2009.

FAUSTINO, Deivison Mendes. A universalização dos direitos e a promoção de equidade: o caso da saúde da população negra. Ciência \& Saúde Coletiva, v. 22 n. 12, 2017. p. 3.8313.840 .

FOUCAULT, Michel. O sujeito e o poder. In: DREYFUS, Hubert. L. e RABINOW, Paul. (Orgs.). Michel Foucault, uma trajetória filosófica: para além do estruturalismo e da hermenêutica. Rio de Janeiro: Forense Universitária, 1995.

GUIMARÃES, Antonio Sergio Alfredo. Depois da democracia racial. Tempo Social: revista de sociologia da USP, v. 18, n. 2, 2006. p. 269-287.

GRANDI, Jaqueline.; DIAS, Miriam Thais Guterres e GLIMM, Simone. Percepções daqueles que perguntam: qual a sua cor? Saúde em Debate [online], v. 37 n. 99, 2013, p. 588-596.

HART, Carl. Um preço muito alto: a jornada de um neurocientista que desafia nossa visão sobre as drogas. Rio de Janeiro: Zahar: 2014.

INSTITUTO BRASILEIRO DE GEOGRAFIA E ESTATÍSTICA (IBGE). Censo Demográfico 2010. Famílias e domicílios. Resultado da amostra. Rio de Janeiro: 2010.

KALCKMANN, Suzana et al. Racismo institucional: um desafio para a equidade no SUS? Saúde e Sociedade [online], v. 16, n. 2, 2007, p. 146-155.

LOPES, Fernanda. Experiências desiguais ao nascer, viver, adoecer e morrer: tópicos em saúde da população negra. In: BATISTA, Luís Eduardo e KALCKMANN, Suzana (Orgs.) Seminário Saúde da População Negra Estado de São Paulo 2004. São Paulo: Instituto de Saúde, 2005.

LOURAU, René. Análise institucional e prática de pesquisa. Rio de Janeiro: Editora da UERJ: 1993.

MAIO, Marcos Chor e MONTEIRO, Simone. Tempos de racialização: o caso da 'saúde da população negra" no Brasil. História, Ciências, Saúde-Manguinhos, Rio de Janeiro, Fundação Oswaldo Cruz, v. 12, n. 2, 2005, p. 419-446.

MARTINS, Alaerte Leandro. Mortalidade materna de mulheres negras no Brasil. Cadernos de Saúde Pública. Rio de Janeiro, v.22, n.11, 2006. p. 2473-2479.

MBEMBE, Achille. Crítica da razão negra. Lisboa: Antígona: 2014.

MBEMBE, Achille. O fardo da raça. Entrevista com Achille Mbembe a Arlette Fargeau e a Catherine Portevin (Philosophie Magazine). São Paulo: n-1 edições: 2018.

MÜLLER, Tânia Mara Pedroso e CARDOSO, Lourenço. Apresentação. In: MÜLLER, Tânia Mara Pedroso e CARDOSO, Lourenço. Branquitude: estudos sobre a identidade branca no Brasil. Curitiba: Appris, 2017.

Revista da ABPN • v. 12, n. Ed. Especial - Caderno Temático: "III ANPSINEP Articulação Nacional de Psicólogas/os Negras/os e Pesquisadoras/es” • outubro de 2020, p. 108-137 
MUNANGA, Kabengele. As ambiguidades do racismo à brasileira. In: KON, Noemi Moritz; SILVA, Maria Lúcia. e ABUD, Cristiane Curi. O racismo e o negro no Brasil: questões para a psicanálise. São Paulo: Perspectiva, 2017.

NASCIMENTO, Abdias. O genocídio do negro brasileiro: processo de um racismo mascarado. São Paulo: Perspectiva: 2017.

NASCIMENTO, Abdias. O quilombismo: documentos de uma militância pan-africanista. São Paulo: Editora Perspectiva; Rio de Janeiro: Ipeafro: 2019.

NOGUEIRA, Isildinha. Baptista. Significações do corpo negro. Tese (Doutorado em Psicologia Escolar e do Desenvolvimento Humano), Universidade de São Paulo, São Paulo, SP, 1998.

OSÓRIO, Rafael Guerreiro. O sistema classificatório de "cor ou raça" do IBGE. (Texto para discussão), TD 0996, Brasília: Instituto de Pesquisa Econômica Aplicada - IPEA. (2003)

PIERUCCI, Antônio Flávio. Cilada da diferença. São Paulo: Programa de Pós-Graduação em Sociologia da FFLCH-USP; Editora 34: 2013.

PIZA, Edith. e ROSEMBERG, Fúlvia. Cor nos censos brasileiros. In: CARONE, Iraí e BENTO, Maria Aparecida da Silva (Orgs.). Psicologia social do racismo: estudos sobre a branquitude e branqueamento no Brasil. Rio de Janeiro: Vozes, 2002.

RAFAEL, Andréa Santos. Perguntar a cor e raça é racismo? O impacto da autoclassificação na rotina de um serviço de saúde pública em São Paulo. Boletim do Instituto de Saúde, São Paulo, n.31, Imprensa Oficial do Estado, 2003.

ROLNIK, Raquel. Territórios negros nas cidades brasileiras (etnicidade e cidade em São Paulo e no Rio de Janeiro). Estudos Afro-Asiáticos, Rio de Janeiro, n. 17, 1989, p. 29-41.

ROSA, Lucia Cristina dos Santos; CAMPOS, Rosana Teresa Onocko. Etnia e gênero como variáveis sombra na saúde mental. Saúde em Debate, Rio de Janeiro, v. 36 n. 95, 2012. p. 648656.

SANTOS, Abrahão de Oliveira. Saúde Mental da população negra: Uma perspectiva não institucional. Revista da Associação Brasileira de Pesquisadores Negros (ABPN), v. 10, n. 24, 2018, p. 241-259.

SANTOS, Josenaide Engracia e SANTOS, Giovanna, Cristina Siqueira. Narrativas dos profissionais da atenção primária sobre a Política Nacional de Saúde Integral da População Negra. Saúde em Debate, Rio de Janeiro, v. 37, n. 99, 2013, p. 563-570.

SARACENO, Benedetto. Manual de saúde mental. São Paulo: Hucitec: 1994.

SCHOLZ, Danielle Celi dos Santos; SILVEIRA, Marta Irís Camargo Messia; SILVEIRA, Paulo Roberto. As práticas racistas no espaço escolar: a influência na saúde mental das crianças negras. Identidade!, São Leopoldo, v. 19, n. 2, 2014, p. 61-74

SCHUCMAN, Lia. Vainer. Entre o encardido, o branco e o branquíssimo: branquitude, hierarquia e poder na cidade de São Paulo. São Paulo: Annablume: 2014.

Revista da ABPN • v. 12, n. Ed. Especial - Caderno Temático: "III ANPSINEP Articulação Nacional de Psicólogas/os Negras/os e Pesquisadoras/es” • outubro de 2020, p. 108-137 
SCHWARCZ, Lilia Moritz. O espetáculo das raças: cientistas, instituições e questão racial no Brasil-1870-1930. São Paulo: Companhia das Letras: 1993.

SCISLESKI, Andrea Cristina Coelho et al. Racismo de Estado e tanatopolítica: reflexões sobre jovens e a lei. Fractal: Revista de Psicologia, v. 28, n. 1, 2016, p. 84-93.

SERRA, Lia Novaes e SCARCELLI, Ianni Regina. Por um sangue bandeirante: Pacheco e Silva, um entusiasta da teoria eugenista em São Paulo. Revista Latinoamericana de Psicopatologia Fundamental, São Paulo, v. 17, n. 1, 2014, p. 85-99.

SILVA, Maria. Lúcia da. O preconceito racial humilha, a humilhação social faz sofrer. Reflexões sobre a construção psíquica do sujeito negro. In: SILVA, Marcus Vinícius de Oliveira (coord.). Psicologia e direitos humanos: subjetividade e exclusão. São Paulo: Casa do Psicólogo; Brasília: Conselho Regional de Psicologia, 2004.

SOARES FILHO, Adauto Martins. O recorte étnico-racial nos Sistemas de Informações em Saúde do Brasil: potencialidades para a tomada de decisão. In: BATISTA, Luís Eduardo; WERNECK, Jurema e LOPES, Fernanda (Orgs.). Saúde da população negra. Brasília: Associação Brasileira de Pesquisadores Negros (ABPN): 2012.

WERNECK, Jurema. Saúde da População Negra. Rio de Janeiro: Crioula: 2010.

Recebido em: $18 / 09 / 2020$

Aceito em: 01/10/2020

Revista da ABPN • v. 12, n. Ed. Especial - Caderno Temático: "III ANPSINEP Articulação Nacional de Psicólogas/os Negras/os e Pesquisadoras/es” • outubro de 2020, p. 108-137 